\title{
Alterations Resulting From Exposure to Mercury in Normotensive and Hypertensive Rats
}

\author{
Luana Urbano Pagan, ${ }^{10}$ Marcelo Diarcadia Mariano Cezar, ${ }^{1,2}$ Ricardo Luiz Damatto ${ }^{1,2}$ \\ Faculdade de Medicina de Botucatu - Universidade Estadual Paulista (UNESP), ${ }^{1}$ Botucatu, SP - Brazil \\ Faculdade de Ciências Sociais e Agrárias de Itapeva (FAIT), ${ }^{2}$ Itapeva, SP - Brazil \\ Short Editorial related to the article: Effects of Chronic Exposure to Mercury on Angiotensin-Converting Enzyme Activity and Oxidative Stress in \\ Normotensive and Hypertensive Rats
}

Mercury is a chemical element still widely used in industrial processes and present in many appliances used daily by the population. However, mercury can be extremely toxic to our body and lead to the development of several diseases such as blindness, deafness, intellectual disability, paralysis, cancer, renal dysfunction, and it can also induce cardiac alterations. ${ }^{1,2}$

Studies have shown that exposure to mercury can cause changes in the cardiovascular system, such as systemic arterial hypertension, coronary dysfunction, cardiac arrhythmia, and increase the risk of myocardial infarction. ${ }^{3,4}$ In humans, high blood mercury levels were correlated with increased systolic and diastolic blood pressure. ${ }^{5}$

Mercury interference can also be observed in several enzymatic, amino acid and antioxidant reactions ( $\mathrm{N}$-acetyl-Lcysteine, alpha-lipoic acid, L-glutathione), reducing oxidative defense and increasing free radicals with consequent increase of oxidative stress. It is also possible that mercury may lead to mitochondrial dysfunction, causing glutathione depletion and rise on lipid peroxidation. ${ }^{6}$

The study by Vassallo et al. ${ }^{7}$ investigated if the chronic exposure to inorganic mercury increases the activity of the angiotensin converting enzyme (ACE) and its relation with oxidative stress in various organs and tissues from hypertensive and normotensive rats. Few studies have evaluated the chronic effects of low doses of inorganic mercury on the ACE activity in organs and tissues of normotensive and hypertensive animals.

The experimental model used by the author was the spontaneously hypertensive rat (SHR), which exhibits

\section{Keywords}

Hypertension; Rats; Mercury Poisoning; Oxidative Stress; Peptidyl-Dipeptidase A; Heart Failure.

Mailing Address: Luana Urbano Pagan •

Universidade Estadual Paulista Júlio de Mesquita Filho - Faculdade de Medicina Campus de Botucatu - Av. Prof. Mário Rubens Guimarães Montenegro, s/n. Postal Code 18618-687, Botucatu, SP - Brazil E-mail: luanapagan@alunos.fmb.unesp.br

DOI: 10.5935/abc.20190025 hypertension similar to human hypertension and has been widely used in several studies for analysis of cardiovascular and biochemical alterations. ${ }^{7-9}$

The hemodynamic evaluation performed in the study by Vassallo et al. ${ }^{7}$ showed that chronic exposure to mercury increased blood pressure in hypertensive animals and left ventricular end-diastolic pressure in normotensive animals. The biometry of the animals demonstrates that hypertensive rats have lower body weight than normotensive animals, data similar to those are found in the literature. ${ }^{9,10}$ The ratio of the brain and lungs normalized by body weight have significantly higher values in hypertensive animals. The weight ratio of the lungs normalized by body weight has been used as a marker of heart failure. ${ }^{11}$ However, exposure to mercury did not cause biometric changes, except for those resulting from the hypertension factor.

Another interesting result shown by Vassallo et al. ${ }^{7}$ was that the concentration of malondialdehyde (MDA) in normotensive animals treated with mercury had higher values in the plasma and the heart, and reduction was reduced in the kidneys. In hypertensive animals treated with mercury, the MDA concentration values are increased in the heart and aorta, and they are reduced in the lungs, brain and kidneys.

The ACE activity in Wistar animals treated with mercury presented higher values only in plasma and heart. Hypertensive animals treated with mercury presented higher values only in plasma and reduced values in the heart, aorta, lungs, brain and kidneys.

Therefore, exposure to mercury caused more significant changes in ACE activity and oxidative stress in SHR rats, determining specific alterations in each organ evaluated and representing a cardiovascular risk factor. The treatment of the animals with mercury exhibited at the end of the experimental period levels similar to those observed in humans exposed to the metal. ${ }^{12}$

However, some questions related to the changes in ACE activity and oxidative stress caused by exposure to mercury are still unclear. More studies are needed to clarify, for example, whether mercury exposure could inhibit ACE activity in situations where it is already elevated, or whether preexisting cardiovascular disease would be aggravated by exposure to mercury. 


\section{References}

1. Guzzi G, la Porta CA. Molecular mechanism triggered by mercury. Toxicology. 2008;244(1):1-12.

2. Genchi G, Sinicropi MS, Carocci A, Lauria G, Catalano A. Mercury exposure and heart diseases. Int J Environ Res Public Health. 2017;14(1):74.

3. Houston MC. The role of mercury and cadmium heavy metals in vascular disease, hypertension, coronary heart disease, and myocardial infarction. Altern Ther Health Med. 2007;13(2):S128-S133.

4. Guallar E, Sanz-Gallardo MI, van't Veer P, Bode P, Aro A, Gómez-Aracena J, et al. Mercury, fish oils, and the risk of myocardial infarction. N Engl J Med. 2002;347(22):1747-54.

5. Valera B, Dewailly E, Poirier P. Environmental mercury exposure and blood pressure among Nunavik Inuit adults. Hypertension. 2009;54(5):981-6.

6. Wildemann TM, Siciliano SD, Weber LP. The mechanisms associated with the development of hypertension after exposure to lead, mercury species or their mixtures differs with the metal and the mixture ratio. Toxicology. 2016 Jan 2;339:1-8.

7. Vassallo DV, Simões MR, Giuberti K, Azevedo BF, o Ribeiro Junior RF, Salaices M, et al. Efeitos da Exposição Crônica ao Mercúrio sobre a Atividade da Enzima Conversora de Angiotensina e Estresse Oxidativo em Ratos Normotensos e Hipertensos. Arq Bras Cardiol. 2019. 112(4):374-380.

8. Cezar MD, Damatto RL, Pagan LU, Lima AR, Martinez PF, Bonomo C, et al. Early spironolactone treatment attenuates heart failure development by improving myocardial function and reducing fibrosis in spontaneously hypertensive rats. Cell Physiol Biochem. 2015;36(4):1453-66.

9. Pagan LU, Damatto RL, Cezar MD, Lima AR, Bonomo C, Campos DH et al. Long-term low intensity physical exercise attenuates heart failure development in aging spontaneously hypertensive rats. Cell Physiol Biochem. 2015;36(1):61-74.

10. Damatto RL, Martinez PF, Lima AR, Cezar MD, Campos DH, Oliveira Jr SA et al. Heart failure-induced skeletal myopathy in spontaneously hypertensive rats. Int J Cardiol. 2013:167(3):698-703.

11. Martinez PF, Okoshi K, Zornoff LA, Oliveira SA Jr, Campos DH, Lima AR, et al. Echocardiographic detection of congestive heart failure in postinfarction rats. J Appl Physiol. 2011;111(2):543-51.

12. Asgary S, Movahedian A, Keshvari M, Taleghani M, Sahebkar A Sarrafzadegan N. Serum levels of lead, mercury and cadmium in relation to coronary artery disease in the elderly: a cross-sectional study. Chemosphere. 2017 Aug; 180:540-4 